\title{
Influence of gastrocnemius-soleus muscle force on sub-MTH load distribution
}

Wen-Ming Chen ${ }^{1 *}$, Victor Phyau-Wui Shim², Taeyong Lee ${ }^{1}$

From 3rd Congress of the International Foot and Ankle Biomechanics Community

Sydney, Australia. 11-13 April 2012

\section{Background}

The gastrocnemius-soleus (G-S) muscle complex, the most dominant extrinsic plantar flexor, plays an important role in the normal weight-bearing function of the foot. The stability and stance-phase placement of the foot can be adversely affected when muscular loads/support are abnormal (e.g. equinus contracture) [1]. This study aims to formulate a three-dimensional musculoskeletal finite element (FE) model of the foot to quantify

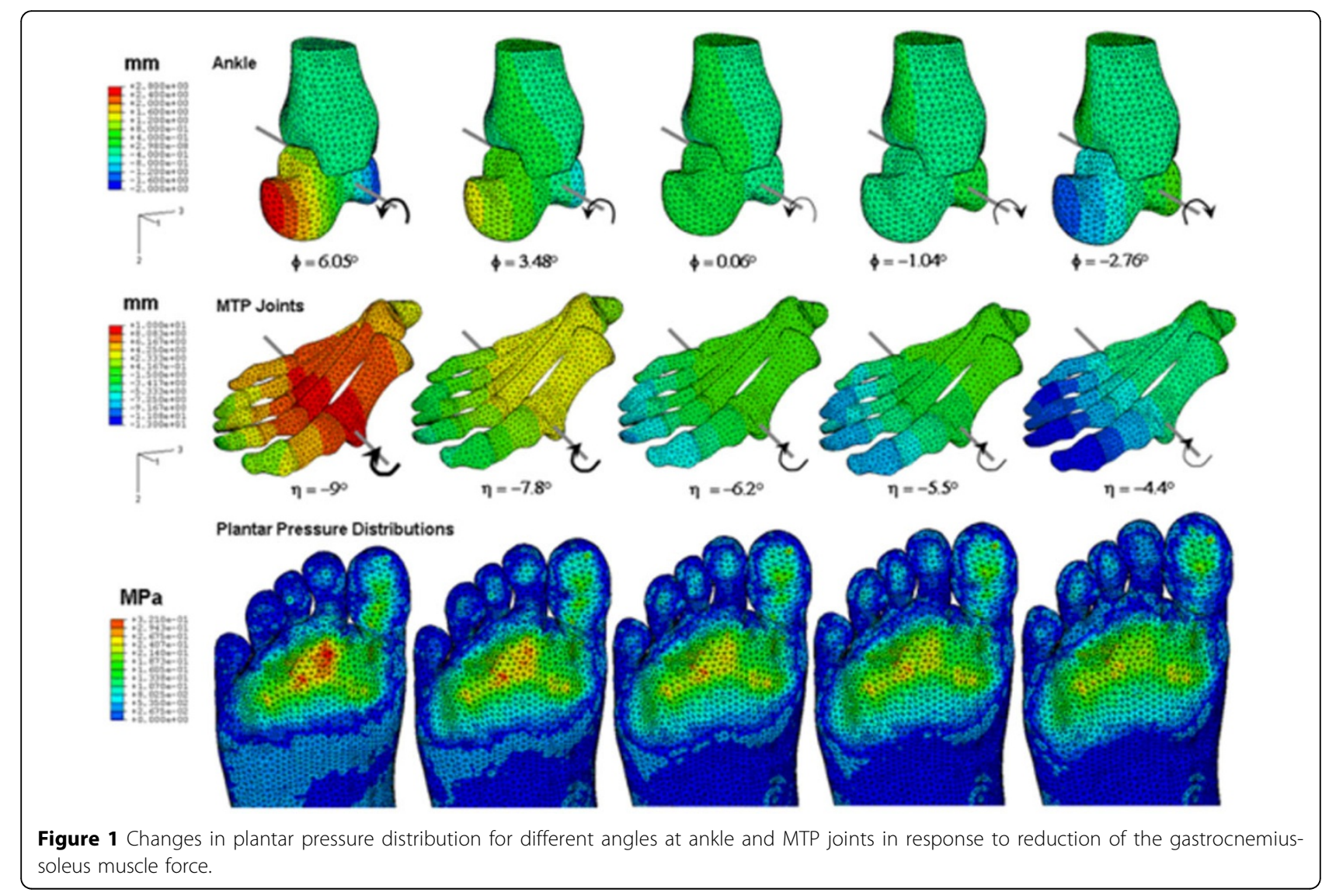

'Division of Bioengineering, National University of Singapore, Singapore

Full list of author information is available at the end of the article

$\odot 2012$ Chen et al; licensee BioMed Central Ltd. This is an Open Access article distributed under the terms of the Creative Commons
Afowed Central any medium, provided the original work is properly cited. 
the influence of G-S muscle force on forefoot metatarsal head (MTH) load distribution.

\section{Materials and methods}

The FE model established corresponds to a muscledemanding posture in heel-rise, with simulated activation of major extrinsic plantar flexors. In a baseline case, the required muscle forces were inversely determined from what would be necessary to generate the targeted ground reaction forces corresponding to known boundary conditions. This baseline model served as a reference for subsequent parametric analysis. The adaptive changes of the foot mechanism (i.e., internal joint configurations and plantar loads distributions) in response to decreased muscle forces in G-S complex (adjusted in a step-wise manner) were analyzed. The muscle force adjustments mimic effects of surgical tendo-Achilles lengthening procedure [2].

\section{Results}

Movements of the ankle and metatarsophlageal joints, as well as the forefoot plantar pressure peaks and the pressure distribution under the metatarsal heads were all found to be extremely sensitive to reduction in the muscle load in the G-S complex. A $40 \%$ reduction in G-S muscle stabilization can result in dorsal-directed rotations by $8.81^{\circ}$ at the ankle and decreased metatarsophalangeal joint extension by $4.65^{\circ}$ (Figure 1 ). The resulting peak pressure reductions at individual MTHs, however, may be site-specific and possibly dependent on foot structure, such as intrinsic alignment of the metatarsals.

\section{Conclusions}

The relationships linking muscular control, internal joint movements, and plantar loading distributions are envisaged to have important clinical implications on tendoAchilles lengthening procedures, and to provide surgeons with an understanding of the underlying mechanism for relieving forefoot pressure in diabetic patients suffering from ankle equinus contracture.

\section{Author details}

Division of Bioengineering, National University of Singapore, Singapore. ${ }^{2}$ Department of Mechanical Engineering, National University of Singapore, Singapor.

Published: 10 April 2012

\section{References}

1. Sutherland DH, Cooper L, Daniel D: The role of the ankle plantar flexors in normal walking. J Bone Joint Surg 1980, 62:354-63.

2. Maluf $\mathrm{KS}$, et al: Tendon Achilles lengthening for the treatment of neuropathic ulcers causes a temporary reduction in forefoot pressure associated with changes in plantar flexor power rather than ankle motion during gait. J Biomech 2004, 37:897-906.
doi:10.1186/1757-1146-5-S1-O26

Cite this article as: Chen et al:: Influence of gastrocnemius-soleus muscle force on sub-MTH load distribution. Journal of Foot and Ankle Research 2012 5(Suppl 1):O26.

\section{Submit your next manuscript to BioMed Central} and take full advantage of:

- Convenient online submission

- Thorough peer review

- No space constraints or color figure charges

- Immediate publication on acceptance

- Inclusion in PubMed, CAS, Scopus and Google Scholar

- Research which is freely available for redistribution

Submit your manuscript at www.biomedcentral.com/submit 